\title{
UMA ANÁLISE TEÓRICA DAS MEDIDAS SANITÁRIAS DE ENFRENTAMENTO DA PANDEMIA DO COVID-19 NO BRASIL: QUEM DECIDE, COMO DECIDE E POR QUÊ?
}

\author{
Natan Figueredo Oliveira* \\ Juraci Mourão Lopes Filho**
}

\section{RESUMO}

Este artigo busca analisar juridicamente o embate existente entre os entes federados acerca das medidas sanitárias de enfrentamento da pandemia do COVID-19 no Brasil. Após uma exposição inicial do contexto da pandemia no país, examinam-se os fundamentos da repartição de competências constitucionais a partir do conceito de normas secundárias do sistema jurídico, com base em pesquisa bibliográfica. Aborda-se o modelo constitucional do federalismo cooperativo e a atuação estatal no suporte fático do direito à saúde como solução. Examinam-se decisões do Supremo Tribunal Federal sobre a competência para fixar medidas sanitárias que confirmam a solução proposta para o conflito federativo.

\section{PALAVRAS-CHAVE}

Federalismo cooperativo; norma secundária; suporte fático do direito fundamental à saúde; COVID-19

\section{A THEORETICAL ANALYSIS OF THE CONTROL MEASURES TO COMBAT THE COVID-19 PANDEMIC IN BRAZIL: WHO DECIDES, HOW DOES IT DECIDE AND WHY?}

\begin{abstract}
This article seeks to legally analyze the conflict between federated entities about the sanitary measures to combat the COVID-19 pandemic in Brazil. In the introduction it exposes the of the pandemic in the country. Then, it examines the fundamentals of the constitutional competence division based on the concept of secondary norms of the legal system, based on bibliographic research. It approaches the cooperative federalism and the state's action in the factual support of the right to health, as a solution. It confirm the proposed solution based on decisions of the Supreme Federal Court on the competence to establish sanitary measures.
\end{abstract}

\section{KEYWORDS}

Cooperative federalism; Secondary rule; Factual support of fundamental right to health; COVID-19

\section{INTRODUÇÃO}

No dia 11 de março de 2020, a Organização Mundial da Saúde - OMS declarou como pandemia a doença provocada por um novo coronavírus, cujos primeiros casos de

1 Mestrando em Processo e Direito ao Desenvolvimento (UNICHRISTUS). Pós-Graduado Lato Sensu em Direito Público (ESMAPE). Juiz de Direito no Estado da Paraíba. E-mail: onatanfigueredo@gmail.com

2 Doutor (UNIFOR) e Mestre (UFC) em Direito Constitucional. Pós-Graduado Lato Sensu em Direito Processual Civil (UFC). Professor da UNICHRISTUS (graduação e pós-graduação). Procurador do Município de Fortaleza. Advogado. E-mail: juracimourao@gmail.com 
contaminação foram relatados na cidade de Wuhan, na China, em 2019. A disseminação pelo mundo foi espantosamente rápida com elevados números de óbitos em vários países, saturando os sistemas de saúde da maior parte deles.

Diante da crise de saúde pública sem precedentes recentes e da ausência de cura ou vacina para a doença, autoridades sanitárias passaram a recomendar medidas preventivas para reduzir a aceleração do contágio e evitar o colapso do sistema de saúde ${ }^{3}$.

As medidas recomendadas dizem respeito ao distanciamento e isolamento social, restrição excepcional de circulação de pessoas, suspensão de atividades escolares, fechamento temporário de estabelecimentos comerciais, entre outras que visam, sobretudo, a evitar a aglomeração de pessoas. Tais medidas de enfrentamento da pandemia são colocadas em prática em decorrência do poder de polícia sanitária da Administração Pública.

Para dar sustentação a esse exercício do poder de polícia foram editadas diversas normas regulamentando as atividades da população, inclusive as atividades empresariais.

No âmbito nacional, a Lei $\mathrm{n}^{\mathrm{o}} 13.979$, de 06 de fevereiro de 2020, dispõe sobre as medidas para enfrentamento da emergência de saúde pública de importância internacional decorrente do coronavírus responsável pelo surto de 2019, nominado de COVID-19. A referida lei apresenta no artigo $3^{\circ}$ um rol exemplificativo de medidas de proteção da coletividade como isolamento, quarentena, determinação de realização compulsória de exames médicos etc, estabelecendo que as medidas restritivas resguardariam o funcionamento dos serviços públicos e atividades essenciais. Para a regulamentação da lei foram editados os Decretos Federais no 10.282, de 20/03/2020, e no 10.288, de 22/03/2020.

\footnotetext{
3 A organização Mundial de Saúde - OMS, levando em conta a experiência dos países que primeiro tiveram de lidar com a pandemia recomendou: "Em primeiro lugar, expandam, treinem e implantem seu sistema de saúde e sua força de trabalho. Em segundo lugar, implementem um sistema voltado a identificar qualquer caso suspeito em nível comunitário. Em terceiro lugar, aumentem a produção, capacidade e disponibilidade de testes da enfermidade. Em quarto lugar, identifiquem, adaptem, equipem instalações de que necessitarão para isolar e tratar pacientes. Em quinto lugar, desenvolvam um plano claro e processos de quarentena. Em sexto lugar, reorientem ('refocus') todo o governo para atuar na supressão e no controle ao COVID-19. Essas medidas são a melhor forma de suprimir e parar a transmissão, para que, quando as restrições forem levantadas, o vírus não surja novamente". Livre tradução. Disponível em https://www.who.int/dg/speeches/detail/whodirector-general-sopening-remarks-at-the-media-briefing-on-covid-19--25-march-2020

https://www.who.int/dg/speeches/detail/who-directorgeneral-s-opening-remarks-at-the-media-briefing-on-covid19---25march-2020. Acesso em 31 mar. 2020.

No Brasil, o Conselho Federal de Medicina divulgou nota destacando a importância de uma ação estruturada do governo e que promovesse a efetiva adesão da população para atender às recomendações consensualizadas internacionalmente: "A contenção da epidemia é o pilar central da estratégia e, embora pareça que as medidas propostas sejam básicas e, portanto fáceis de serem implementadas, a adesão maciça e tempestiva necessária para o sucesso da estratégia demandará logística complexa e forte articulação entre o governo brasileiro e a sociedade civil organizada para acompanhar o dia a dia do enfrentamento à epidemia, retirando barreiras quando necessário, criando normas e promovendo a efetiva adesão da população às recomendações globais." Disponível em http://portal.cfm.org.br/. Acesso em 26 abr. 2020.
} 
Ocorre que a referida lei apresentou conceitos de isolamento e de quarentena restritos às pessoas doentes, contaminadas ou suspeitas de estarem contaminadas (artigo $2^{\circ}$, I e II) e, ainda, dispôs que as medidas de isolamento social e de quarentena dependeriam de imposição por ato do Ministério da Saúde ou de gestores locais de saúde autorizados pelo Ministro da Saúde (artigo $3^{\circ}, \S 7^{\circ}$ ), o que, na prática, não atendeu às recomendações das autoridades sanitárias para o contingenciamento do vírus e combate ao avanço da doença.

Por isso, considerando as suas respectivas realidades regionais e locais, vários governadores e prefeitos estabeleceram medidas restritivas com a edição de atos que promoveram quarentena e isolamento mais amplos do que aquilo que restou estabelecido pelo governo federal ${ }^{4}$.

Em reação, o Presidente da República editou a Medida Provisória ${ }^{\circ}$ 926, de 20/03/2020, alterando a Lei n ${ }^{\circ}$ 13.979/2020, para outorgar a si próprio, com exclusividade, a definição dos serviços públicos e atividades essenciais. Assim, a rigor e na prática, governadores e prefeitos não poderiam, sem o ato do Poder Executivo Federal, impor, por exemplo, restrição da locomoção interestadual e intermunicipal por rodovias, tampouco dispor sobre essencialidade de serviços ou fechamento de atividades comerciais, ainda que estivessem diante de alto risco de contágio do COVID-19.

Surgiu, então, intenso debate cujo pano de fundo é o desenho do federalismo e a atribuição de competências comuns e concorrentes dada pela Constituição a cada ente federativo. Qual é o ente competente para lidar com a emergência sanitária que se apresentou e exercer o correspondente poder de polícia? Trata-se de verdadeiro conflito federativo sobre o qual já se pronunciou o Supremo Tribunal Federal, como ocorreu, por exemplo, no julgamento das medidas cautelares exaradas na Ação Direta de Inconstitucionalidade $n^{\circ}$ 6341, de relatoria do Ministro Marco Aurélio Mello, e nas Ações de Descumprimento de Preceito

\footnotetext{
4 Exemplificativamente, no Estado da Paraíba, o Decreto Estadual no 40.122, de 13/03/2020 decretou situação de emergência. Na sequência, o Decreto Estadual $n^{\circ} 40.134$, de 20/03/2020, declarou estado de calamidade pública, em razão de crise de saúde pública decorrente da pandemia e o Decreto Estadual $\mathrm{n}^{\circ} 40.135$, de 20/03/2020 traçou excepcionais medidas de restrição ao funcionamento do comércio, determinando, em todas as cidades com casos confirmados de coronavírus (COVID-19), o fechamento temporário de academias, ginásios, centros esportivos, shopping centers, galerias comerciais, bares, restaurantes, casas de festas, casas noturnas, boates, estabelecimentos similares, cinemas, teatros, circos, parques de diversão, agências bancárias, casas lotéricas, lojas, etc. No Estado de São Paulo, o Decreto no 64.881, de 22/03/2020, decretou quarentena no contexto da pandemia do COVID-19 (Novo Coronavírus), providências complementares de restrição de atividades para evitar a propagação do vírus, suspendendo o atendimento presencial ao público em estabelecimentos comerciais e prestadores de serviços, especialmente em casas noturnas, shopping centers, galerias e estabelecimentos congêneres, academias e centros de ginástica, ressalvadas as atividades internas; o consumo local em bares, restaurantes, padarias e supermercados, etc.
} 
Fundamental n 669 e n ${ }^{\circ}$ 672, de relatoria dos Ministros Luís Roberto Barroso e Alexandre de Morais, respectivamente.

Em síntese, a Suprema Corte esclareceu que as competências para o cuidado com o direito fundamental à saúde, comum e concorrente, mitigam o traço centralizador da União e impõem que os entes atuem em cooperação e respeito à autonomia de cada um e à ausência de hierarquia entre União, Estados, Distrito Federal e Municípios.

Apesar das definições apresentadas pelo Supremo Tribunal Federal, com a reafirmação do federalismo cooperativo, observa-se que o tema tem sido pouco compreendido $^{5}$. Por isso, a despeito dos cruzamentos de interesses e relações políticas, econômicas e médicas que envolvem a citada pandemia, o presente artigo pretende responder, com fundamentos jurídicos, às seguintes indagações: Quem decide sobre as medidas sanitárias de enfrentamento da pandemia do COVID-19? Como se deve decidir, ou melhor, qual a substância da decisão que estabelece tais medidas? Esses critérios foram efetivamente observados? Por que existe uma espécie de predefinição do poder de decisão?

Apesar da ordem de questionamentos apresentada acima e no título deste artigo, para fins didáticos e evolução do raciocínio, as respostas serão apresentadas da última para a primeira indagação, partindo-se das bases da teoria do direito, pois envolve a definição do alcance das normas secundárias de competência, bem como se as normas primárias que regulamentam as condutas na pandemia o fizeram de modo a respeitar os direitos fundamentais envolvidos.

Inicia-se com a apresentação das razões da existência de normas definidoras de competências no ordenamento jurídico e que visam superar controvérsias e atuações arbitrárias das autoridades públicas, que não estão acima umas das outras nem fora do alcance da Constituição, adotando-se a lição de H. L. A. Hart para quem o ordenamento jurídico é um sistema composto de normas primárias e secundárias. Na sequência, apresenta-se a proposta de Scott J. Shapiro para conceber as normas secundárias como um plano compartilhado de organização do comportamento das autoridades públicas, que estabelece a ordem constitucional e, portanto, está na base do ordenamento jurídico, composto de mecanismos institucionais de autolimitação do poder.

5 Não é incomum que se repita que os Estados e Municípios estão se sobrepondo indevidamente ao posicionamento da União. O Presidente da República Jair Bolsonaro, em discurso de abertura da Assembleia das Nações Unidas, em 22 de setembro de 2020, chegou a ratificar essa desinformação, afirmando: "Por decisão judicial, todas as medidas de isolamento e restrições de liberdade foram delegadas a cada um dos 27 governadores das unidades da Federação. Ao Presidente, coube o envio de recursos e meios a todo o País". Disponível em https://g1.globo.com/politica/noticia/2020/09/22/veja-a-integra-do-discurso-de-jair-bolsonaro-naabertura-da-75a-assembleia-geral-da-onu.ghtml. Acesso em 22 de set. de 2020. 
Em seguida, examina-se a moldura constitucional que trata do federalismo cooperativo, com as suas promessas e limitações, a fim de identificar o âmbito de atuação de cada um dos entes federados e percorre-se, de forma breve, o suporte fático do direito fundamental a ser tutelado, por ter relação direta com a atuação destes entes no contexto das ações de enfrentamento da pandemia, que consubstanciam matéria de saúde pública.

A metodologia utilizada na elaboração do artigo considerou artigos científicos, doutrinas específicas sobre a matéria e consulta a decisões do Supremo Tribunal Federal, com abordagem qualitativa, porquanto se desejou analisar o conteúdo dos votos dos ministros sem fazer avaliação quantificável.

\section{AS NORMAS SECUNDÁRIAS E ALOCAÇÃO DE PODERES E COMPETÊNCIAS}

O Estado Democrático de Direito está alicerçado na declaração de direitos fundamentais, na existência de separação dos poderes e no federalismo e suas regras de distribuição de poderes e competências. Todos estes pilares estão previstos na Constituição e têm por função limitar o poder e, consequentemente, evitar a tirania e a arbitrariedade. Além dessa função sobre o controle do poder político, a distribuição de competências constitucionais exerce papel fundamental em um sistema jurídico complexo, pois soluciona o problema da inércia no disciplinamento de condutas, outorgando poderes a determinadas autoridades com o objetivo de definir como alterar, criar e revogar normas de condutas.

As normas secundárias do federalismo limitam o poder estatal ao repartir os poderes de criar normas de condutas entre entes dos governos central, regional e local, que no Brasil são representados pela União, Estados, Distrito Federal e Municípios. E mais, prever competências comuns e concorrentes, forçando uma ação coordenada, com vistas a melhor realizar os objetivos perseguidos.

A razão desse compartilhamento de poder está na base da existência do ordenamento jurídico e para explicar tal concepção invoca-se a lição de H. L. A. Hart (2009), que convida o leitor a imaginar a existência de uma sociedade na qual a convivência dos seus membros é baseada apenas em normas primárias, que impõem deveres e exigem a prática ou a abstenção de atos. Tal estrutura social simples apresenta defeitos de incerteza, inércia (resultando em um caráter estático) e ineficiência, que, de forma simplificada, dizem respeito à falta de definição de critérios de quando uma regra integra ou não o sistema jurídico, à impossibilidade de modificação dessas regras sem um lento processo costumeiro e que não atende às 
necessidades sociais emergentes e à ausência de um mecanismo para determinar a satisfação ou a violação de quaisquer das regras (HART, 2009).

Segundo Hart (2009), a introdução de um tipo específico de normas, que chamou de normas secundárias, resolveria esses defeitos ou problemas de uma estrutura social mais simples e permitiria vislumbrar as características próprias de um sistema jurídico.

Em outras palavras, para que um sistema jurídico exista enquanto tal deve haver uma combinação entre normas primárias e secundárias. As normas primárias são aquelas que tratam do que se deve fazer ou não, impondo uma obrigação ou um dever, consistindo numa regra de conduta. As normas secundárias, a seu turno, são normas sobre a identificação, criação, extinção, alteração e aplicação das normas primárias.

\begin{abstract}
Assim, pode-se dizer que todas as normas secundárias se situam num nível diferente daquele das normas primárias, pois versam todas sobre essas normas; isto é, enquanto as normas primárias dizem respeito a atos que os indivíduos devem ou não devem praticar, todas as normas secundárias se referem às próprias normas primárias. Especificam como as normas primárias podem ser determinadas, introduzidas, eliminadas e alteradas de forma conclusiva, e como estabelecer conclusivamente o fato de terem sido transgredidas. (HART, 2009, p. 122)

(..)

Mas, exatamente pelo fato de um sistema jurídico ser uma união complexa de normas primárias e secundárias, essas provas não são suficientes para descrever as diferentes relações entre a pessoa e o direito envolvidas na existência desse sistema. Precisam ser suplementadas por uma descrição da relação entre as autoridades do sistema e as normas secundárias que lhes dizem respeito como tais. (HART, 2009, p. 148).
\end{abstract}

Ao explicar as normas secundárias, Hart (2009) esclarece que elas são de três tipos: de reconhecimento (que resolve os problemas de incerteza), de modificação ou alteração (que soluciona a inércia) de adjudicação ou julgamento (que asseguram a eficiência). Em linhas gerais e para os propósitos deste estudo, pode-se dizer que as normas de reconhecimento identificam quais são as normas primárias de obrigação e, ainda, que nos sistemas jurídicos modernos tais normas incluem uma Constituição escrita e envolvem um processo legislativo e os precedentes judiciais. As normas de modificação permitem alterar as normas existentes, introduzir novas normas primárias para orientar a vida do grupo e eliminar normas antigas. As normas de julgamento conferem poder a certos órgãos para aplicar as normas primárias e determinar a sua satisfação, especificando o método ou procedimento a ser seguido (HART, 2009).

Assim, tais normas secundárias são necessárias para distinguir os sistemas jurídicos de outras coleções de normas como jogos, religiões, clubes, corporações, etiquetas etc e mesmo dão os parâmetros para definição dos poderes das autoridades públicas (SHAPIRO, 2009). 
A partir das ideias de Hart sobre as normas secundárias e mais especificamente sobre aquelas do tipo normas de reconhecimento, Scott J. Shapiro (2009) propõe a reconcepção das normas secundárias como elementos de um plano compartilhado mais amplo e que estabelece a ordem constitucional de um sistema jurídico. A função desse plano seria orientar o comportamento das autoridades legais, mediante a prévia especificação do papel que cada um deve desempenhar na sua atividade pública.

Assim, além do desempenho das funções propostas por Hart para a norma de reconhecimento, esta também teria por escopo resolver um problema de "incerteza de segunda ordem" referente à alocação de poder. A "incerteza de primeira ordem” diria respeito à escolha das regras que o grupo social é obrigado a seguir e a "incerteza de segunda ordem" diria respeito à legitimidade das autoridades oficiais para resolver as incertezas de primeira ordem (SHAPIRO, 2009).

Segundo Shapiro (2009), Hart deixou de considerar que, nas comunidades mais complexas e que não estão ligadas apenas por laços familiares, crenças ou valores, a incerteza surge não apenas quanto ao que deve ou não ser feito, mas também sobre quem recai a autoridade para resolver tais questões.

Nessa quadra, a existência das normas secundárias resolve, como dito, o problema da incerteza de segunda ordem de uma maneira menos complexa e controversa do que ocorreria se houvesse dependência de uma abordagem improvisada e ad hoc. Isto é, em vez de se exigir que os membros da comunidade deliberem, negociem ou tentem impor a distribuição adequada do poder político no momento em que surgir a dúvida, basta apelar para as normas secundárias do sistema jurídico que determinam as funções das autoridades ou dos entes que compõem o sistema (SHAPIRO, 2009).

Shapiro (2009) propõe uma teoria do direito como um plano ou planejamento que chamou de "planning theory of law", sustentando que é através de um planejamento compartilhado que as atividades coletivas são orientadas e organizadas, criando-se uma malha entre as autoridades oficiais. Desse modo, as normas secundárias do sistema que constituem esse plano compartilhado, impõem e conferem os poderes de criar e aplicar o direito, inclusive com as definições do que os membros do grupo devem fazer nas atuações conjuntas e nos casos em que não devem interferir na atuação dos outros.

O objetivo deste estudo não comporta maior incursão na teoria desenvolvida por Shapiro, mas a sua apresentação se revela suficiente para compreender que em sistemas jurídicos como o brasileiro, a norma secundária deve ser identificada também por meio das 
normas constitucionais que alocam poderes de criação e de aplicação de normas e por aquelas que estabelecem os deveres dos entes e das autoridades estatais, por exemplo, habilitando a União, através do Presidente da República, ou os Estados, através dos governadores, para ações específicas, cada um deles com papel ou atribuição definido no plano compartilhado que originou o ordenamento e que consta da Constituição, comprometendo-os a agir conjuntamente ou a não interferir um na parte que toca ao outro.

Assim, com a conformação do conceito de norma secundária, passa-se a demonstrar como a Constituição apresenta um planejamento para a atuação em casos como o enfrentamento da pandemia.

\section{A DISTRIBUIÇÃO DE COMPETÊNCIAS E FEDERALISMO COOPERATIVO}

Frequentemente tem sido noticiado que a definição das medidas de enfrentamento da pandemia do COVID-19 no Brasil gerou tensão entre os entes federados, numa disputa para estabelecer ações que apresentem respostas mais favoráveis à proteção da saúde ou mais preocupadas com a liberdade individual e a economia.

As edições de atos de prefeitos, governadores e do Presidente da República pretendendo normatizar, de modo mais ou menos rigoroso, as medidas de fechamento ou restrição do comércio ou de circulação de pessoas bem exemplificam o cenário que se instaurou. Após o pico mais agudo do surto, debate-se sobre as medidas de retomada gradual das atividades.

A solução jurídica para o conflito tem como pressuposto a existência de normas secundárias e do plano compartilhado por ocasião da implementação da Constituição, o que revela o desenho do federalismo, possibilitando que autoridades federais, estaduais e municipais compartilhem poder e responsabilidade e respeitem o âmbito de atuação um do outro.

Por isso, é relevante rememorar que o Brasil possui um federalismo cooperativo, um sistema com compartilhamento do poder de estrutura tríplice formada pela União, Estados, Distrito Federal e Municípios (artigos $1^{\circ}$ e 18 da Constituição da República), com objetivo de se alcançar equilíbrio no exercício do poder. Nesse sentido:

O federalismo cooperativo se caracteriza por uma atuação conjunta dos entes federados que passam a ter zonas comuns de atuação, não só no plano legislativo, mas também material, de implementação de políticas públicas. Abandona-se o entendimento de atuação de esferas paralelas e autônomas de autoridades para se impor uma atuação conjugada em vários setores, permitindo e fomentando, inclusive, pactos, convênios e acordos em áreas que não sejam expressamente compartilhadas já no plano constitucional. Assim, não só uma divisão de competências legislativas e materiais com zona de intersecção e comunhão, mas também alianças pactuadas e 
específicas para soma de esforços, passaram a ser comuns na vida das federações; tudo sob a coordenação geral do ente central, que passou a ter mais ascendência no jogo federativo, sendo uma característica marcante desse modelo, uma necessidade inarredável, conquanto não traduzida em termos jurídicos, mas certamente políticos. (LOPES FILHO, 2019, p. 38).

A forma de Estado Federal está estruturada a partir da união indissolúvel de mais de uma organização política no mesmo espaço territorial do Estado, com um processo de distribuição constitucional de poderes por meio da repartição de competências irrenunciáveis que constitui o próprio núcleo da noção de Estado Federal (CUNHA JÚNIOR, 2008).

Nesse particular, quando se fala em competência deve-se considerar o poder de atuação atribuído aos órgãos e agentes por normas secundárias contidas da Constituição Federal com o fim de realizarem as tarefas de que são incumbidos (CANOTILHO, 1989), sem existir hierarquia entre os entes federados nem supremacia de competências para órgãos centrais.

Em geral, o parâmetro estabelecido para a consecução das funções por cada um dos entes federados é o critério da predominância do interesse, pelo qual à União cumpre atuar nas matérias e questões de predominante interesse geral nacional, aos Estados cabem as matérias e assuntos de predominante interesse regional e aos municípios os assuntos de interesse local. Entretanto, há situações que apresentam dificuldade de identificar qual o tipo de interesse envolvido, se local, regional ou nacional e, por isso, a Constituição concebe técnicas para a divisão adequada (CUNHA JÚNIOR, 2008).

As técnicas de divisão ou repartição encontradas das normas secundárias conjugam poderes ou competências enumeradas e remanescentes. Por exemplo, nos Estados Unidos e na Argentina o federalismo implica a enumeração dos poderes da União deixando os remanescentes para os Estados. No Canadá, ao contrário, são enumerados os poderes dos Estados e os remanescentes competem à União. Já na Índia são enumeradas todas as competências (SILVA, J., 2005). O Brasil

adota um sistema complexo que busca realizar o equilíbrio federativo, por meio da enumeração dos poderes para a União (arts. 21 e 22), com poderes remanescentes para os Estados (art. 25) e poderes definidos indicativamente para os Municipios (art. 30), mas combina com essa reserva de campos específicos (nem sempre exclusivos, mas apenas privativos), possibilidades de delegação (art. 22, parágrafo único), áreas comuns em que prevêem atuações paralelas da União, Estados, Distrito Federal e Municípios (art. 23), e setores concorrente entre União e Estados, em que a competência para estabelecer políticas, diretrizes gerais ou normas gerais cabe à União, enquanto que se defere aos Estados e até aos Municípios a competência suplementar (SILVA, J., 2005, p. 479).

Em matéria de saúde pública, a Constituição contempla a competência comum da União, Estados, Distrito Federal e Municípios para "cuidar de saúde e assistência pública" (artigo 23, II) e concorrente entre União, Estado e Distrito Federal para legislar sobre 
"proteção e defesa da saúde" (artigo 24, XII), podendo os Municípios suplementarem a legislação sobre a matéria de acordo com o interesse local (artigo 30, I).

A competência comum é a de cunho paralelo ou simultâneo, isto é, pode ser exercida concomitantemente pelos entes federados, objetivando a cooperação e sinergia entre eles. $\mathrm{O}$ que justifica tal forma de atuação é garantir uma cobertura mais ampla e isenta de lacunas, mediante políticas públicas e ações em áreas sensíveis, como ocorre com a saúde (SARLET; MARINONI; MITIDIERO, 2017).

É relevante anotar que o federalismo consubstancia um processo de tomada de decisão, determinando o local de tomada de decisão do governo (KNAUER, 2020). Todavia, o controle da substância de tal decisão é feito a partir do catálogo de direitos fundamentais e mais especificamente pelo direito fundamental envolvido na tomada de decisão. O exame deste ângulo será apresentado mais adiante.

Por ser o locus de um processo decisório e não uma ideologia (KNAUER, 2020), o federalismo objetiva um equilíbrio entre governo central e governo local, por razões que envolvem as dificuldades de atuação em amplos territórios geográficos e peculiaridades da população de determinado lugar.

As dificuldades desse modelo de organização e divisão do poder surgem pela atuação simultânea desordenada. Mas, no Brasil o federalismo é qualificado por ser cooperativo. Entender o federalismo com tal qualificação não importa na consideração de características humanas e altruístas como bondade e respeito, mas significa que existe a obrigação de observância dos parâmetros previamente definidos no texto constitucional para a ação de forma coordenada e para o cumprimento do seu viés democrático.

Em suma, as limitações do federalismo cooperativo aparecem não porque ele possibilita atuações conjuntas, mas porque os atores institucionais podem não estar comprometidos com o mesmo objetivo a ser compartilhado. Por isso, no contexto das ações do governo para enfrentar a pandemia do COVID-19, tais divergências foram evidenciadas a ponto de serem submetidas ao crivo do Supremo Tribunal Federal.

Com vistas a proteger o delicado equilíbrio federal, o Supremo Tribunal Federal é encarregado de promover o controle da constitucionalidade dos atos normativos. Se um Estado Federal é uma união de direito constitucional, seus conflitos são conflitos constitucionais e, portanto, jurídicos, daí porque é característica dessa forma de Estado existir um tribunal com competência para solucionar conflitos federativos. Assim, em termos hartianos, a norma secundária que estabelece os poderes para assegurar a eficácia das outras 
normas de competência, indica o Supremo Tribunal Federal como autoridade apropriada para tal solução.

Na Ação Direta de Inconstitucionalidade n 6341, o Ministro Marco Aurélio Mello concedeu parcialmente a medida cautelar para assentar que a Medida Provisória ${ }^{\circ}$ 926/2020, que altera a Lei $n^{\circ} 13.979 / 2020$, com a finalidade de mitigar a crise internacional da pandemia que chegou ao Brasil, não afasta a competência concorrente, em termos de saúde, dos Estados e Municípios. A medida cautelar foi submetida a referendo pelo plenário da Corte, que a confirmou e, por maioria, acolheu o voto do Ministro Edson Fachin para dar interpretação conforme a Constituição ao artigo $3^{\circ}, \S 9^{\circ}$ da Lei $n^{\circ} 13.979 / 2020$, no sentido de preservar a atribuição de cada esfera de governo diante da possibilidade do Presidente da República dispor, mediante decreto, sobre serviços públicos e atividades essenciais (BRASIL, STF, 2020).

$\mathrm{Na}$ ocasião, ficou assentado que, pelos contornos das competências dos entes da federação no âmbito do federalismo cooperativo da Constituição, as medidas recomendadas pela Organização Mundial de Saúde como isolamento e quarentena podem ser tomadas por todas as pessoas que tenham competência material para cuidar da saúde, em conformidade com os artigos 23, II e 198, I. Vale lembrar que possuir competência material implica, no jogo federativo brasileiro, o poder de editar as normas de conduta respectiva.

O Supremo Tribunal Federal destacou que, pelas regras de distribuição das competências da Constituição, a União exerce a prerrogativa de afastar a competência dos demais entes quando, de forma nítida, veicular norma que organiza a cooperação federativa, seja por meio de lei geral (artigo $24, \S 1^{\circ}$ ) seja através de lei complementar (artigo 23, parágrafo único). Ademais, cabe à União "planejar e promover a defesa permanente contra as calamidades públicas" (artigo 21, XVIII). Entretanto, nenhuma preferência ou exclusividade sustenta a omissão de qualquer das esferas de governo.

Com efeito, a Lei ${ }^{\circ}$ 13.979/2020 não estabeleceu regras de cooperação nem criou ações coordenadas, desconsiderando o papel e a importância da atuação dos demais entes federados (MAZZUOLI; FRAZÃO, 2020) e, nessa perspectiva, o Supremo Tribunal Federal, para preservar o equilíbrio federativo e pela existência de normas secundárias próprias do sistema jurídico brasileiro, assegurou que a interpretação da legislação federal sobre a crise sanitária no Brasil não pode subtrair a competência para cuidar da saúde pública incumbida aos demais entes. Isso é óbvio, pois a Lei $\mathrm{n}^{\circ}$ 13.979/2020 deve ser compreendida como uma 
norma primária de conduta, a qual não poderia, de forma alguma, interferir nas normas secundárias de competência, que, por definição, possuem hierarquia superior.

No mesmo sentido, a medida cautelar concedida em parte na Ação de Descumprimento de Preceito Fundamental $n^{\circ} 672$ pelo Ministro Alexandre de Morais pontificou que o Poder Executivo Federal não deve afastar, unilateralmente, as decisões dos governos estaduais, distrital e municipais que adotaram ou venham a adotar, no âmbito de seus respectivos territórios e no exercício de suas competências constitucionais, medidas como isolamento social, suspensão de atividades escolares, restrições ao funcionamento do comércio e outros mecanismos reputados eficazes para reduzir o número de infectados e de óbitos pelo COVID-19 (BRASIL, STF, 2020).

Desse modo, ainda que o respeito ao federalismo represente uma profusão de normas e medidas em todos os níveis de governo para o enfrentamento da pandemia no país, as ações são possíveis simultaneamente se coordenadas e fundadas na proteção dos direitos fundamentais, na medida em que todos os entes federados são obrigados a implantar, no âmbito de suas respectivas competências, as políticas públicas essenciais, notadamente as que digam respeito ao direito à saúde.

Nesse ponto é que se deve investigar o conteúdo das decisões tomadas pelas diferentes esferas de governo para aferir a compatibilidade com a proteção do direito fundamental em risco e, assim, explicar as razões pelas quais a Constituição interdita a possibilidade de um ente federado atuar para frustrar o critério da cooperação ou para diminuir o âmbito de proteção do direito.

Tem-se, então, as normas secundárias bem claras, segundo as quais cabem a todos os entes federativos expedirem normas primárias de conduta a fim se combater a pandemia de coronavírus, o que se deve dar por cooperação, cada ente atuando dentro de sua área de interesse: a União com medidas de alcance nacional, os Estados-membros cotejando aquilo que é de interesse regional e os Municípios e o Distrito Federal regular as condutas de interesse local. Como dito, não são atuações estanques e incomunicáveis, daí por que se fala em preponderância e não exclusividade de interesse de cada ente federativo.

\section{A ATUAÇÃO ESTATAL NO SUPORTE FÁTICO DO DIREITO À SAÚDE}

A Constituição contempla um catálogo de direitos fundamentais que, ao lado da distribuição de competências federativas, também constitui um mecanismo de limitação do poder estatal, direcionando as atividades das autoridades públicas. Por isso, para compreender 
que o conteúdo das medidas de enfrentamento da pandemia do COVID-19 deve ser conduzido pelo caminho de proteção da saúde, deve-se antes entender em que consiste o suporte fático de um direito fundamental.

Virgílio Afonso da Silva (2009) explica que o suporte fático, no viés abstrato, é o conjunto de fatos ou atos do mundo descritos em uma determinada norma (primária de conduta, na terminologia hartiana), a qual prevê uma consequência jurídica para a sua realização ou ocorrência e, no viés concreto, é a ocorrência no mundo da vida dos atos ou fatos da norma abstrata. Para a identificação adequada do suporte fático do direito, ele propõe responder às seguintes questões: $1^{\circ}$ ) $\mathrm{O}$ que é protegido? $2^{\circ}$ ) Contra o quê? $3^{\circ}$ ) Qual a consequência jurídica que poderá ocorrer? $4^{\circ}$ ) O que é necessário ocorrer para que a consequência também ocorra?

Nessa linha de raciocínio, entende-se que aquilo que é protegido é o âmbito de proteção do direito fundamental, contra o que é protegido é a intervenção, em geral estatal. A consequência pode ser a exigência de cessação de uma intervenção ou a de omissão ou de proteção deficiente.

$\mathrm{Na}$ análise do suporte fático dos direitos fundamentais, uma primeira pergunta a ser respondida é, como se viu: o que é protegido por esses direitos? Intuitivamente, poder-se-ia pensar que, por exemplo, no caso do direito à saúde, o protegido é pura e simplesmente a saúde dos indivíduos ou da coletividade. Essa intuição é guiada pelo termo "proteção". Pensar dessa forma é, no entanto, tentar transportar para a esfera dos direitos sociais o mesmo raciocínio que subjaz ao suporte fático das liberdades públicas em sua dimensão negativa. Para perceber que esse transporte não é possível basta imaginar que, se o protegido, no exemplo dado, é simplesmente a saúde dos indivíduos ou da coletividade, a intervenção estatal nesse âmbito protegido teria que ser uma intervenção na saúde das pessoas, ou seja, um ato estatal que restringisse ativamente a saúde dos indivíduos. Como se sabe, os problemas relacionados aos direitos sociais não são dessa ordem. O que ocorre, nesse âmbito, é a falta de realização dos direitos, decorrente em geral de uma omissão estatal ou de uma ação insuficiente. Em suma: tanto o conceito do que é protegido quanto o conceito de intervenção tem que ser modificados.

Se "proteger direitos sociais" implica uma exigência de ações estatais, a resposta à pergunta "o que faz parte do âmbito de proteção desses direitos?" tem que, necessariamente, incluir ações. "Proteger direitos", nesse âmbito, significa "realizar direitos". Por isso, pode-se dizer que o âmbito de proteção de um direito social, é composto pelas ações estatais que fornecem a realização desse direito.

Também o conceito de intervenção estatal precisa ser invertido. No caso da dimensão negativa das liberdades públicas, "intervir" significa agir de forma restritiva ou reguladora no âmbito de proteção de uma liberdade. Aqui, na esfera dos direitos sociais, é justamente o contrário: "intervir", nesse sentido, é não agir ou agir de forma insuficiente (SILVA, V., 2009, p. 77).

Assim, é correto dizer que o direito fundamental à saúde gera o direito à prestação de saúde para o indivíduo e o dever para o Estado de garantir tal direito com políticas públicas que, inclusive, visem à redução do risco de doenças e outros agravos (MENDES; BRANCO, 2018). 
No enfrentamento da pandemia do COVID-19, é intuitivo que o direito fundamental em risco é a saúde, cujo suporte fático resultante da combinação do seu âmbito de proteção e intervenção, revela a necessidade de fazer cessar a proteção deficiente e assegurar que os titulares do direito não sejam expostos indevidamente ao risco de contágio.

Em consequência, observados os parâmetros já elencados sobre a alocação de competências dos entes federativos em matéria de saúde pública, não é possível, à luz da Constituição, que a atuação de um dos entes imponha uma atuação exclusiva deficitária ou frustre a ação de outros. Afinal, todos têm o dever de implantar, no âmbito de suas respectivas competências, as políticas públicas essenciais.

Logo, tanto a União está impedida de tolher a atuação dos Estados e Municípios que adotem medidas de proteção da saúde quanto os Estados e Municípios estão impedidos de, a pretexto de tratar de assuntos locais, frustrarem as ações protetivas implementadas por outros entes.

Veja-se que alguém poderia supor, com base na existência das normas secundárias que amparam o federalismo cooperativo, que os Municípios estariam autorizados a editar ato contrário ao que tenha sido concebido em âmbito estadual, na medida em que já se afirmou que para o enfrentamento da pandemia há autorização constitucional para atuação simultânea ou paralela. Contudo, o conteúdo do ato ou da medida é que não pode violar o âmbito de proteção do direito social envolvido.

Ilustrativamente, imagine-se que determinado Município, defendendo a sua competência comum para tratar de matéria de saúde e, ainda, a sua autonomia para tratar de assuntos de interesse local, resolva editar ato autorizando o funcionamento indiscriminado das atividades comerciais em seu território, a despeito da existência de outro ato do respectivo Estado que proíbe o funcionamento de uma série de atividades comerciais não essenciais e que promovem a aglomeração de pessoas durante a pandemia.

No exemplo hipotético, a atuação do Município revela-se indevida. Primeiro, porque o trato de assuntos locais reservados aos municípios diz respeito aos serviços que lhe são próprios, ou seja, assuntos unicamente relacionados à comunidade local e geridos pelo ente municipal, considerando que cada cidade tem as suas peculiaridades, o modo de vida, os costumes mais tradicionais ou mais cosmopolitas etc. Segundo, porque um determinado tema pode ser reputado de interesse local e, ainda assim, não se conformar na realidade e esfera de atuação local. 
Ora, é induvidoso que o regramento sobre funcionamento do comércio, por ser de interesse local, é de competência do Município, conforme súmula vinculante $\mathrm{n}^{\mathrm{o}} 38$ do Supremo Tribunal Federal. Ressalva-se, porém, que a referida competência contempla temperamentos, de modo que o Município não pode, por exemplo, definir o horário de funcionamento das instituições financeiras no seu território, pois os interesses não podem ser conformados pela realidade local, dependendo de operações e negócios que se realizam em todo o território nacional e, portanto, a matéria é reservada à competência da União ${ }^{6}$.

$\mathrm{Na}$ hipótese apresentada, o antagonismo sobre o funcionamento ou fechamento de determinados estabelecimentos comerciais no período da pandemia não diz respeito à regulação de atividade ou interesse exclusivo ou predominante do Município, porquanto a realidade não se conforma no âmbito do território municipal. Ou seja, a emergência de saúde pública e o combate da pandemia ultrapassam os limites da circunscrição do Município, de modo que o fechamento do comércio como política pública de saúde implementada pelo Estado não pode ser frustrada pelo Município sob pena de provocar proteção deficiente ao direito a ser tutelado ${ }^{7}$.

Destarte, se todos os entes federados devem cooperar para a execução da tarefa determinada pela Constituição de garantir o direito à saúde, inclusive, com políticas públicas voltada à redução do risco de doenças e outros agravos, não pode nenhum deles se eximir de implementá-las ou dificultar a implementação por outros, pois o impacto recairá evidentemente sobre todas as esferas de governo (ROVIRA apud BERCOVIC, 2004, p. 60).

É por isso que na medida cautelar concedida na Ação de Descumprimento de Preceito Fundamental no 669 pelo Ministro Luís Roberto Barroso ficou claro que o direito à saúde impõe ao poder público que não coloque em risco o direito à saúde, não se admitindo a adoção de medidas contrárias às recomendações das autoridades sanitárias e que favoreçam o contágio e a propagação do vírus (BRASIL, STF, 2020). Espera-se, por imposição constitucional, atuação cooperativa e observância do suporte fático do direito fundamental.

\footnotetext{
6 Nesse sentido, a súmula $\mathrm{n}^{\circ} 19$ do Superior Tribunal de Justiça, segundo a qual “a fixação do horário bancário, para atendimento ao público, é da competência da União". No mesmo sentido: STF, RE 118363/PR.

7 Nesse sentido, "Reclamação Constitucional. Competência. Conflito entre Decretos Estadual e Municipal acerca da determinação de fechamento de estabelecimento comercial. Alegada ofensa à Súmula Vinculante 38. Ausência de estrita aderência. Situação excepcional de pandemia do COVID-19. Efeitos deletérios que extrapolam limites territoriais e requerem medidas amplas e coordenadas entre os entes federativos. Descaracterização do interesse meramente local. Competência concorrente da União, Estados e Municípios para questões de saúde pública. Art. 23, II da Constituição Federal. Medida Cautelar na ADI 6.341/DF. Reclamação que se julga improcedente". (STF, Reclamação no 39.790, Relator Ministro Luiz Fux, j. 22/04/2020, DJe 23/04/2020).
} 


\section{CONSIDERAÇÕES FINAIS}

O desafio humano da atualidade é o enfrentamento de uma pandemia, mas poderia ser outro também atual como mudanças climáticas, atenção a refugiados, etc. Problemas como esses reclamam soluções urgentes para a tutela dos direitos fundamentais e encontram na Constituição o guia para a atuação dos entes e autoridades públicas.

A realidade brasileira apresentou um aprofundamento do problema da pandemia em decorrência do atrito entre o Poder Executivo Federal e os governos estaduais e municipais nas propostas de condução da crise, principalmente com relação ao poder de polícia sanitária. Como resultado, vive-se uma experiência que multiplicou e diversificou as medidas de distanciamento social, quarentena, restrição ao comércio e outras, variando de acordo com o nível de propagação da doença e também de acordo com o código postal.

Contudo, se os grupos sociais não foram conduzidos de forma coordenada ou uniforme, o problema não está na falta de definição de como se deve agir em tais situações, mas sim na inobservância e descumprimento das normas pertinentes pelos agentes públicos. Nessa linha, não é verdadeiro o discurso de que o Supremo Tribunal Federal tenha eximido qualquer esfera federativa de suas responsabilidades para proteção da saúde pública.

Não se desconhece que algum ceticismo quanto à ciência ou questões relacionadas à tendência de priorizar liberdades econômicas, mesmo numa emergência sanitária, estão diretamente ligadas ao agravamento do desafio experimentado pelos brasileiros.

Porém, é recomendável tornar ainda mais evidente que a existência do plano compartilhado de competências na base do ordenamento jurídico merece ser observado também em situações imprevistas, transformadas e novas como a que se apresenta.

Numa sociedade complexa, cuja existência e funcionamento dependem do direito e, consequentemente, das normas secundárias que afastam a incerteza sobre qual o direito aplicável e quais autoridades são legítimas para aplicá-lo, é com olhos voltados para Constituição que se deve buscar as soluções para os antagonismos. Isso impede que posturas mais conservadoras ou mais progressistas do governante atual sirvam para reformulação de competências com concentração de poderes ou omissões frente a direitos fundamentais.

O momento de crise não seria e não é o mais propício para alocar e negociar competências entre entes e autoridades, tampouco para definir açodadamente a fundamentalidade do direito envolvido.

O poder de compartilhamento de governo origina a ordem constitucional e está definido na Constituição por meio de um federalismo cooperativo com limites rígidos de 
atuação, seja em períodos de normalidade institucional e social, seja em condições extraordinárias, e revela quando a atuação é estanque (competências exclusivas e privativas) e quando é conjunta (competências comuns e concorrentes).

Sendo assim, o exercício do poder deve encontrar a validade e se justificar na própria Constituição, com a interação entre os entes, com mecanismos de autocontrole e com a efetivação de direitos considerados fundamentais, como a saúde.

Nesse contexto, provocada a jurisdição, o Supremo Tribunal Federal definitivamente não impediu a atuação do Poder Executivo Federal ou de qualquer outra esfera, mas reconheceu que existe uma clara divisão de responsabilidades e atribuições concebidas e predefinidas no texto constitucional e que não permitem a atuação insuficiente no suporte fático do direito à saúde, tampouco a ingerência indevida.

O entendimento externado pela Suprema Corte, ao menos nas primeiras decisões proferidas e citadas acima, é no sentido de que a tensão do federalismo na crise da pandemia deve ser solucionada mediante atuação uniformizada e harmônica dos entes federados nas diversas instâncias e com medidas consentâneas com as recomendações das autoridades sanitárias, e, na dúvida, fazer prevalecer a saúde da população.

O acirramento de divergências político-partidárias não pode ser creditado nas decisões do Poder Judiciário que protegem o delicado equilíbrio federal num momento igualmente delicado para a população.

Enfim, é pela teoria do direito que se compreende que o sistema jurídico efetivamente funciona ou deve funcionar porque a competência e o comportamento dos atores legais já estão previamente distribuídos por meio das normas secundárias para aplicar as normas primárias.

Espera-se que o entendimento sobre o modelo do federalismo cooperativo e as posições que ocupam União, Estados, Distrito Federal e Municípios com respectivas competências alocadas por normas que fundam o ordenamento jurídico e que o entendimento sobre a fundamentalidade do direito à saúde e o seu suporte fático, cuja intervenção representa uma proibição de proteção deficiente, possibilitem superar dúvidas sobre as medidas sanitárias de enfrentamento da pandemia.

\section{REFERÊNCIAS}

BERCOVICI, Gilberto. Dilemas do Estado Federal Brasileiro. Porto Alegre: Livraria do Advogado, 2004. 
BRASIL. Lei $\mathbf{n}^{\mathbf{0}}$ 13.979, de 06 de fevereiro de 2020. Dispõe sobre as medidas para enfrentamento da emergência de saúde pública de importância internacional decorrente do coronavírus responsável pelo surto de 2019. Brasília-DF: Presidência da República, [2020]. Disponível em: http://www.http://www.planalto.gov.br/ccivil_03/_ato20192022/2020/lei/113979.htm. Acesso em: 1 abr. 2020.

BRASIL. Superior Tribunal de Justiça. Súmula no 19. A fixação do horário bancário, para atendimento ao público, é da competência da União. Brasília, DF. Superior Tribunal de Justiça, [1990]. Disponível em: https://www.stj.jus.br/sites/portalp/Jurisprudencia/Sumulas. Acesso em: 19 abr. 2020.

BRASIL. Supremo Tribunal Federal. Ação Direta de Inconstitucionalidade no 6341. Requerente: Partido Democrático Trabalhista Brasileiro. Relator: Ministro Marco Aurélio Mello. Brasília, DF, 24 de março de 2020. Decisão monocrática. Disponível em http://portal.stf.jus.br. Acesso em 16 abr. 2020.

BRASIL. Supremo Tribunal Federal. Ação Direta de Inconstitucionalidade n⿳0 6341. Requerente: Partido Democrático Trabalhista Brasileiro. Relator: Ministro Marco Aurélio Mello. Brasília, DF, 15 de abril de 2020. Referendo da decisão liminar julgado em sessão plenária realizada por videoconferência. Disponível em https://www.youtube.com/watch?v=QLcKK-LiHDw. Acesso em 16 abr. 2020.

BRASIL. Supremo Tribunal Federal. Ação de Descumprimento de Preceito Fundamental $\mathbf{n}^{\mathbf{0}}$ 669. Segunda Turma. Requerente: Rede Sustentabilidade. Relator: Ministro Ministro Luís Roberto Barroso. Brasília, DF, 24 de março de 2020. Decisão monocrática. Disponível em http://portal.stf.jus.br. Acesso em 16 abr. 2020.

BRASIL. Supremo Tribunal Federal. Ação de Descumprimento de Preceito Fundamental $\mathbf{n}^{\mathbf{0}}$ 672. Segunda Turma. Requerente: Conselho Federal da Ordem dos Advogados do Brasil. Relator: Ministro Alexandre de Morais. Brasília, DF, 31 de março de 2020. Decisão monocrática. Disponível em: http://portal.stf.jus.br. Acesso em 16 abr. 2020.

BRASIL. Supremo Tribunal Federal. Reclamação Constitucional no 39.790. Reclamante: Município de Pedro Canário. Reclamado: Juiz de Direito da Vara Única de Pedro Canário. Relator Ministro Luiz Fux, 22 de abril de 2020. Disponível em: http://portal.stf.jus.br/processos/detalhe.asp?incidente=5883180. Acesso em: 25 abr. 2020.

BRASIL. Supremo Tribunal Federal. Súmula Vínculante no 38. É competente o Município para fixar o horário de funcionamento de estabelecimento comercial. Brasília,DF. Supremo Tribunal Federal, [2010]. Disponível em:

http://www.stf.jus.br/portal/jurisprudencia/menuSumario.asp?sumula=2183. Acesso em: 19 abr. 2020.

CANOTILHO, José Joaquim Gomes. Direito constitucional. 4 ed. Coimbra: Almedina, 1989.

CUNHA JUNIOR, Dirley. Curso de Direito Constitucional. Salvador: Juspodivm, 2008.

HART, H. L. A. O Conceito de Direito. São Paulo: Editora WMF Martins Fontes, 2009. 
KNAUER, Nancy J., The COVID-19 Pandemic and Federalism: Who Decides? (May 9, 2020). New York University Journal of Legislation and Public Policy, Vol. 23, No. 1, 2020. Disponível em http://dx.doi.org/10.2139/ssrn.3599239. Acesso em 01 jun. 2020.

LOPES FILHO, Juraci Mourão. Competências Federativas na Constituição e nos precedentes do STF. Salvador: Juspodivm, 2019.

MAZZUOLI, Valério de Oliveira; FRAZÃO, Hugo Abas. O que a pandemia pode ensinar para Itália e Brasil sobre federalismo? Disponível em https://www.conjur.com.br/2020mai-12/frazao-mazzuoli-federalismo-durante-covid-19. Acesso em 11 jun. 2020.

MENDES, Gilmar Ferreira; BRANCO, Paulo Gustavo Gonet. Curso de Direito Constitucional. São Paulo: Saraiva, 2018.

SARLET, Ingo Wolfgan; MARINONI, Luiz Guilherme; MITIDIERO, Daniel. Curso de Direito Constitucional. São Paulo: Saraiva, 2017, E-Book.

SHAPIRO, Scott J., What is the Rule of Recognition (and Does it Exist)?. The Rule of Recognition and the U.S. Constitution, Matthew Adler, Kenneth Himma, eds., Oxford University Press, 2009; Yale Law School, Public Law Working Paper N. 184. Disponível em https://ssrn.com/abstract=1304645. Acesso em 01 jun. 2020.

SILVA, José Afonso da. Curso de Direito Constitucional Positivo, 25. ed. São Paulo: Malheiros, 2005.

SILVA, Virgílio Afonso da. Direitos fundamentais: conteúdo essencial, restrições e eficácia. São Paulo: Malheiros, 2009. 